\title{
Examining organizational learning in schools: The role of psychological safety, experimentation, and leadership that reinforces learning
}

\section{Citation}

Higgins, Monica, Ann Ishimaru, Rebecca Holcombe, and Amy Fowler. forthcoming 2012.

Examining organizational learning in schools: The role of psychological safety, experimentation, and leadership that reinforces learning. Journal of Educational Change,

\section{Published Version}

http://www.springerlink.com/content/6468554757511435/

\section{Permanent link}

http://nrs.harvard.edu/urn-3:HUL.InstRepos:5372114

\section{Terms of Use}

This article was downloaded from Harvard University's DASH repository, and is made available under the terms and conditions applicable to Open Access Policy Articles, as set forth at http:// nrs.harvard.edu/urn-3:HUL.InstRepos:dash.current.terms-of-use\#OAP

\section{Share Your Story}

The Harvard community has made this article openly available.

Please share how this access benefits you. Submit a story.

\section{Accessibility}


Examining Organizational Learning in Schools: The Role of Psychological Safety, Experimentation, and Leadership that Reinforces Learning

\author{
Monica Higgins \\ Ann Ishimaru \\ Rebecca Holcombe \\ Amy Fowler
}

Harvard Graduate School of Education 


\begin{abstract}
This study draws upon theory and methods from the field of organizational behavior to examine organizational learning (OL) in the context of a large urban U.S. school district. We build upon prior literature on OL from the field of organizational behavior to introduce and validate three subscales that assess key dimensions of organizational learning that build upon and extend prior education research: psychological safety, experimentation, and leadership that reinforces learning. Data from 941 teachers across 60 schools in this urban district suggest that organizational learning is an underlying condition which is expressed by teacher perceptions of subfactors of psychological safety, experimentation, and leadership that reinforces learning. Implications for adopting the conceptual framework and methods employed in this research for studying organizational learning and school change are discussed.
\end{abstract}

Key Words: Organizational learning, psychological safety, experimentation, leadership, school change, teacher perceptions, confirmatory factor analysis 


\section{Introduction}

In response to the No Child Left Behind Act, many schools focused their efforts on implementing new programs to help them reach performance goals outlined by their states’ accountability systems. And yet, these efforts have not yielded the results reformers anticipated (Giles \& Hargreaves, 2006). As scholars and practitioners now agree, new initiatives and structures alone are unlikely to lead to lasting change. Rather, sustainable change in schools is a function of the beliefs, norms, and expectations of those working within those schools, as well as their capacity for learning (Elmore, 2002). Over and beyond identifying effective curricula or requiring educators to use data to improve performance, schools must strengthen their internal capacity to manage change processes in order to reach high levels of performance. This is a different approach to educational change; it is one that goes beyond a focus on compliance or support for programmatic change to a focus on organizational learning and capacity building within schools (Hopkins, Harris, \& Jackson, 1997; Stoll, 2009).

Unfortunately, many schools still lack what Stoll (1999; 506) has called an “internal capacity” for learning - the capacity to engage in and sustain all members of the school community with the shared purpose of improving student learning. As David Cohen (1990) observed, "Unfortunately, most schools offer teachers little room for learning, and little help in managing the problems that learning would provide” (p.327). This was true a decade ago when the National Commission on Teaching and America’s Future concluded that in order to realize significant improvements in student learning, low-performing schools needed to be redesigned as learning organizations_-as organizations capable of supporting the learning of all members and of continually improving practice (Fullan, 1995; Senge, 1990). Linda Darling-Hammond (1996), commenting on the Commission's report, explained 
It is now clear that most schools and teachers cannot produce the kind of learning demanded by the new reforms - not because they do not want to, but because they do not know how, and the systems they work in do not support their efforts to do so (p. 3). Understanding how to create school systems that can themselves be "learning organizations" to improve instruction and enhance student achievement has remained an elusive phenomenon. As Leithwood, Leonard, and Sharratt (1998) commented, “Although there are compelling reasons to view schools from an organizational learning perspective and some powerful theoretical tools to shape such a perspective, empirical evidence is thin, to say the least” (p. 268). Today, the reviews of organizational learning (OL) theory continue, and the application of these theories to improve our understanding of the dynamics of district instructional reform remains of significant interest (e.g., Boyd, 2008). Still, scholars conclude that OL work has become more fragmented and suggest that future research take strides toward integrating parallel streams of research that have proceeded on this subject (Knapp, 2008). Further, researchers call for more and better empirical research to understand how the process of capacity building unfolds in schools (Copland \& Knapp, 2006; Gallucci, 2008).

This article responds to recent calls to action for research on organizational learning in education. First, we draw upon research in organizational behavior to introduce and validate a survey instrument for measuring key aspects of organizational learning in the context of schools. The instrument was designed by scholars in the fields of management and organizational behavior. For this study, we selected a subset of scales to validate building upon recent research about the role of the sociocultural environment of schools in supporting change (e.g., Bryk et al., 2010; McLaughlin \& Talbert, 2006). We adapted the subscales for use in schools based on preliminary, cognitive pretesting and subsequent factor analyses, and offer the modified scales 
here as a tool for understanding how, from the perspective of teachers, organizational learning is manifest at a school site. This study serves the goal of providing better conceptual integration of prior organizational learning theories because it draws both on research on cognitive dimensions of organizational learning (e.g., Argyris \& Schon, 1996) and sociocultural learning theory (e.g., Honig, 2008).

We begin with a brief review of the literature on organizational learning and its linkages to organizational change, and then propose specific areas of opportunity that remain for education research. In particular, drawing from organizational behavior research by Garvin, Edmondson, and Gino (2008), we investigate three elements of their research outlining dimensions or "building blocks" of organizational learning that may be especially important elements of a learning environment for teachers in urban school settings: "psychological safety" (Edmondson, 1999: 350), experimentation, and leadership that reinforces learning. We use confirmatory factor analysis (CFA) to validate each of the subscales that sample these constructs and then test the degree to which they are essential components of the secondary construct of organizational learning. Specifically, we examine how the constructs of psychological safety, experimentation, and leadership that reinforces learning are related to organizational learning in schools and explore the implications of these relationships for both future educational research and practice.

\section{Background and Theory}

Numerous excellent reviews exist on the topic of organizational learning as it applies to schools and school systems (see, for example, Cousins, 1996; Leithwood \&Aitken, 1995; Leithwood, Leonard, \& Sharratt, 1998, and the dedicated to organizational learning in American 
Journal of Education, Boyd, 2008). Further, recent books on learning communities (e.g., McLaughlin \& Talbert, 2006) and school improvement in large urban districts (e.g., Bryk et al., 2010) provide extensive reviews of the literature and important updates on related research. In this section, rather than provide another extensive literature review, we focus our attention on the OL literature that we believe may be especially useful in the study of education reform.

\section{Background}

Although definitions abound regarding the term "organizational learning," scholars generally concur that organizational learning refers to a higher order of collective learning that extends beyond a single individual; individuals within an organization thus learn from one another and/or group(s) (see Gallucci, 2008).

The term, “organizational learning," itself was first introduced by March and Simon in 1958 and later became popular as students and colleagues of March and Simon plunged into the study of knowledge management. Much of this work focused on information search, acquisition, integration, and assimilation in organizations. Knowledge and information, including prior experiences, were viewed as resources for organizations (generally in the private sector) that could help organizations “learn” and develop (Levinthal \& March, 1993; Levitt \& March, 1988). Of particular interest were the rational, information processing or sense-making cycles that people engage in when they learn (Huber, 1991). For example, extensive research has looked at "absorptive capacity” which refers to an individual's or organization's capacity to recognize the value of new kinds of information absorbing it into existing habits of minds or ways of organizing (Cohen \& Levinthal, 1990). Overall, this has been a largely cognitive perspective on organizational learning that has aimed to understand how people think about complex problems, 
solve them, and in addition, avoid errors (e.g., Argyris \& Schon, 1996).

In contrast to this cognitive stream of research on organizational learning, another stream of research has proceeded in parallel which has been referred to by some as sociocultural learning theory (e.g., Honig, 2008). This OL research stream has focused on individuals' social interactions within organizations (e.g., Vygotsky, 1978). From this vantage point, people learn primarily through the socially embedded activities, behaviors, and practices that they engage in (Wertsch, 1996). Thus, rather than study how people cognitively do or do not process information effectively, scholars in this tradition focus specifically on how social practices shape individuals’ learning. For example, research in this stream has studied how people or organizations assist others in learning (e.g., Cole \& Wertsch, 1996) and how communities of practice or learning communities emerge and evolve (e.g., Stein \& Coburn, 2008). Overall, the emphasis in this stream of work has been on the social processes of learning in organizations (see Knapp, 2008, for a review).

Recently, these two OL research streams have come closer together in perspective. As Honig (2008) describes, the New Institutional Sociologists have built upon early cognitive scientific approaches to studying organizational learning by examining how social and cultural contexts influence individuals' searches for information and sense-making (e.g., Van de Ven \& Polley, 1992; see Honig, 2008, for a review). However, despite this convergence, educational scholars who study organizational learning continue to call for further integration between these two perspectives (e.g., Knapp, 2008). In the particular context of schools and school change, scholars point out that negotiation and internal conflict are part and parcel of growth and learning in schools and so, in-depth examinations of teacher behaviors and practices are essential to understanding organizational learning (e.g., Gallucci, 2008; Hubbard et al., 2006). At the same 
time, education scholars have written extensively about the merits of effective data gathering and analyses on the part of teachers in order to effect change in schools and school systems (e.g., Boudett, City, \& Murnane, 2005) suggesting that the cognitive perspective on OL is also valuable. Thus, these recent streams of research also emphasize the need for a more integrative approach to understanding OL in schools.

\section{An Integrative Stance}

We concur with recent educational scholars' assessments of the bifurcation in the organization learning literature and the merits of considering information related processes along with more social related practices that individuals engage in at work. Interestingly, at precisely the same time that this call for integration has come in the education literature (e.g., Knapp, 2008), literature in the adjacent field of organizational behavior proposed a theoretical model that takes into consideration both of these approaches. This framework, proposed by Garvin, Edmondson, and Gino in 2008, suggests that in order to understand organizational learning, we need to consider several "building blocks” (p. 2): (1) a “supportive learning environment” (p. 3) (one in which individuals feel psychologically safe, value differences, are open to new ideas, and have time for reflection); (2) "concrete learning processes and practices” (p. 3) (including the creation, collection, and transfer of information, experimentation, and analyses); and (3) "leadership that reinforces learning” (p. 4) (including leader behaviors such as listening attentively and encouraging multiple points of view) These building blocks were developed based upon organizational research and described as "essential for organizational learning and adaptability” (Garvin, Edmondson, \& Gino, 2008, p. 2).

Garvin, Edmondson, and Gino (2008) introduced this OL framework in a practitioner 
journal for management scholars, but the full model has not yet been tested. In their recent article, Garvin and colleagues proposed a series of questions associated with each building block designed for use in both the private and public sectors to measure the extent to which employees report that an organization - and units within an organization - possess the conditions the authors feel are necessary for organizational learning. Garvin and colleagues’ (2008) hypothesized model incorporates both cognitive and sociocultural dimensions of organizational learning.

Garvin, Edmondson, and Gino’s model echoes some of the recent research on OL in education. For example, their approach aligns with the work of Peter Senge (1990) in schools, which—similar to his work on private sector organizations—has emphasized systems thinking, shared vision, and understanding interdependency and change. Similarly, work on professional learning communities (PLCs) in schools identifies characteristics of successful PLCs that include facilitative leadership, participative decision making, shared vision and commitment, and collaborative activity (Giles \& Hargreaves, 2006; Hord, 1997; Imants, 2003; Louis, Marks, \& Kruse, 1996; Marks \& Louis, 1999; Stoll et al., 2006). Recent research on teacher learning communities in particular stresses the interdependence of teacher's work and the importance of school culture to adult and student learning (e.g., McLaughlin \& Talbert, 2006). Garvin and colleagues' model also mirrors education research that takes a more cognitive approach and emphasizes management and information processes (e.g., Honig, 2004). Thus, in many respects, this instrument integrates both OL research streams as called for by recent education research.

In addition, Garvin and colleagues’ model attempts to refine our understanding of organizational climate as a key factor in promoting learning and change. In particular, they suggest ways in which their proposed building blocks influence the organization’s "learning 
environment” (Garvin, Edmondson, \& Gino, 2008, p. 5). Psychological safety, an aspect of the learning environment of an organization, describes the comfort of teachers in speaking up and asking questions, key organizational dynamics within which collective learning takes place (Edmondson, 1999). This added dimension has the potential to build upon research in education showing that open and reflective dialogue among teachers is central to building effective professional learning communities in schools (Bryk et al., 1999).

Garvin and colleagues' attention to social factors, or conditions for learning, mirrors education literature on the social factors that shape teaching and learning, such as politics and values, that make up the social realities of teachers' work (McLaughlin, Talbert, \& Bascia, 1990). Research in urban school contexts has examined specific relationships between social trust within a school, professional community, and a school's capacity for innovation and experimentation (Bryk et al., 1999; Bryk et al., 2010). For example, Silins and colleagues (2002), drawing on Australian data from their Organisational Learning and Leadership Questionnaire, found that having a trusting and collaborative climate within a school positively impacted student outcomes such as engagement and participation in school. Goh and colleagues (2006) extended this work using the Goh and Richards (1997) Organizational Learning Survey to investigate whether schools tend to examine previous mistakes and errors as part of their process of crafting strategic responses to the challenges of school improvement. Their findings suggest that only good news tends to be shared in schools, and in fact, some school cultures do not uniformly support constructive criticism or challenges to past practice. Bryk and Schneider (2003) note that open and honest conversations among colleagues about what does and does not work requires high levels of relational trust and a sense of safety for teachers to expose their vulnerabilities in front of each other. 
In the current study, we extend this recent education research by bringing in key aspects of Garvin and colleague's (2008) model to assess the organizational learning climate, processes, and leadership in schools. In particular, we investigate and apply one subscale in each of the three building blocks in Garvin and colleagues' model: "psychological safety,” “experimentation,” and “leadership that reinforces learning” (p. 5).

Psychological Safety (PS). Over the past decade, organizational behavior scholars such as Edmondson have found that certain learning conditions such as "psychological safety," the feeling that one can safely speak up and ask for help, are associated with important organizational outcomes such as decreased numbers of errors and improved organizational systems and processes indicative of organization level learning (Edmondson, 1999, 2003). Edmondson suggests that when work teams promote psychological safety by, for example, encouraging employees to ask questions or treat mistakes as opportunities for learning, employees are more likely to take the kinds of risks associated with breakthroughs or gamechanging innovations in practice (Edmondson, 1999).

Although related concepts have been studied in schools and districts, the literature would be strengthened by examining teachers’ perceptions of psychological safety, which may be tied to a school organization's ability to engage all members in purposeful, sustained learning to improve practice. For instance, in their four-factor nested model of organizational learning, Sillins et al. (2002) examined the extent to which people feel free to take initiative and risks as a key mediator of leadership effects on student outcomes, yet little is known about the school environment around disagreements and help-seeking. Indeed, recent education research calls for future research that investigates ways of reducing defensiveness such as providing an environment that is "safe" for admitting mistakes and that rewards individuals for trying out new 
approaches to instructional practice (Goh et al., 2006). Introducing and validating the construct of psychological safety would address this call and contribute to our understanding of how certain kinds of organizational climates can facilitate learning in schools.

Experimentation (EXP). A second dimension of the Garvin, Edmondson, and Gino (2008) model that we pull out for special consideration in this context is "experimentation.” This particular element is part of Garvin and colleagues' “learning processes and practices” (p. 3) building block and aligns well with the cognitive strand of organizational learning research. A great deal of recent education research has investigated processes for the collection, creation, analysis, transfer, and application of information and knowledge in schools (Schechter, 2008; Stoll et al., 2006) including recent research on the social networks that enable innovation in schools (Moolenaar, Daly, \& Sleegers, in press).

The research is less clear on what experimentation and innovation look like in schools and how prevalent teachers feel experimentation and innovation actually are, although some recent work by the Chicago Consortium for School Research has examined teacher attitudes about trying out new practices, staying positive, and taking responsibility for school improvement (Bryk et al., 2010). Specifically, the CCSR innovation scale indicates teachers' orientations towards continual learning and new ideas as well as their willingness to be part of an active learning environment (Chicago Consortium for School Research, n.d.). However, the focus has often been on teacher attitudes and orientations rather than teacher perceptions about new behaviors and practices that are enacted schoolwide. Moreover, it is not clear whether teachers see experimentation and innovation as the same construct; rather, the focus in some of the work on innovation in education has been on gathering and assessing appropriate data for teaching and learning. For example, recent research by Schechter (2008) using his 
Organizational Learning Mechanisms (OLM) scale has examined in-depth how information is acquired, analyzed, disseminated, stored, retrieved, and then "put to use” by teachers in elementary schools. The final item, "put to use," includes an assessment of how teachers change the curriculum based upon feedback they receive (Schechter, 2008, p. 162). Still, in this example, as in others, much less is known about the extent to which teachers "try out" or “experiment” with new ideas and instructional practices in schools. Adding this component of "experimentation" to our assessment of OL in schools would extend prior OL research by enabling scholars to better understand what role experimentation plays in the context of organizational learning. That said, the recent emphasis on standardization and centralization of instruction in an era of high stakes accountability raises questions about what experimentation looks like in schools and who actually engages in experimentation and at what level. Garvin and colleagues' (2008) items, as adapted here, attempt to capture teacher perceptions of experimentation at the school level.

Leadership That Reinforces Learning (LTRL). In addition, we pull out a third component in the Garvin, Edmondson, and Gino (2008) model which is "leadership that reinforces learning.” In previous years, the literature on leading district reform has focused primarily on theories of alignment rather than theories of organizational learning. The perspective has been that the leader's primary responsibility is to ensure that all facets of the school system such as its structure, staffing, and curriculum are aligned with specific agreed upon targets or goals for change. With recent emphasis on compliance with centralized reform initiatives such as No Child Left Behind, this pressure to execute against specific targets has only increased. Yet as Knapp (2008) recently argued, this perspective fails to capture the complexities of leading schoolwide reform. Challenges abound for school leaders today including the 
unevenness of capacity in schools, lack of resources, incomplete and ambiguous information, and competing stakeholder agendas. Consequently, it comes as no surprise to education scholars such as Knapp that scholars and practitioners alike have now turned to the "construct of learning to embrace the challenge of reforming districts” (Knapp, 2008, p. 524). Here, we address this need for empirical research on the role of school leaders in facilitating organizational learning by considering the role of the principal in creating conditions for organizational learning in schools.

Each of the leadership items in the Garvin, Edmondson, and Gino (2008) model are consistent with the idea espoused in education research that leaders, such as superintendents and principals, should not only be good learners themselves, they should facilitate learning in their teachers (Collinson, Cook, \& Conley, 2006; Johnson, 1996). Therefore, the Garvin model moves us beyond leadership theories centered on organizing to execute, to leadership that centers on organizing to learn (see Edmondson, 2008, on organizing to learn).

Recent literature on educational leadership has begun to focus on the key role of leaders in developing teachers' capacity, though few instruments examine specific leadership behaviors associated with facilitating organizational learning amongst teachers schoolwide. For example, the Vanderbilt Assessment of Leadership in Education (VAL-ED) examines the extent to which principals support, implement, and monitor communities of professional practice and develop cultures of learning for students (Porter et al., 2010). Similarly, Leithwood and Jantzi’s (2006) transformational leadership instrument probes whether principals support and encourage collaborative work and the consideration of new ideas. In both cases, however, little is known about specific leadership behaviors that reinforce a learning climate amongst school personnel.

In the present research, we single out these three dimensions to add to the complementary streams of literature described above, and we test Garvin and colleagues' (2008) conceptual 
framework and instrument for measuring organizational learning. Garvin and colleagues’ (2008) hypothesized model of the relationship between the proposed building blocks and organizational learning is based upon prior research on OL in organizational behavior but has yet to be validated, or, for our purposes, adapted and then validated for the context of education. Moreover, it is unclear whether the dimensions of interest (psychological safety, experimentation, and leadership that reinforces learning) are preconditions for organizational learning or manifestations of OL; thus, a deeper understanding of this relationship requires empirical testing. We modified and validated subscales for each of the three dimensions of interest: psychological safety (as measured by 3 items), experimentation (as measured by 3 items), and leadership that reinforces learning (as measured by 6 items). We then explored the relationship of each of these subscales to the larger construct of organizational learning. Thus, our empirical research question was: What is the relationship between psychological safety, experimentation, and leadership that reinforces learning with regards to organizational learning? Specifically, we asked:

1. Are the subscales of psychological safety (PS), experimentation (EXP), and leadership that reinforce learning (LTRL) discrete subfactors of the second-order factor of organizational learning?

2. Are the subfactors (PS, EXP, LTRL) necessary intermediaries to organizational learning?

3. What is direction of the relationship between organizational learning and the subfactorsubfactors of (psychological safety, experimentation, and leadership that reinforces learning)?

\section{Data}

The present study uses survey data from 941 teachers in a large urban district in the United States. The district is representative of the largest urban districts in the country with over 
100,000 students enrolled in more than 500 schools and a predominately low-income, minority population. The survey items used for this study were included in a larger pilot survey designed to provide principals with feedback from teachers on their performance.

The survey instrument was administered by the district in electronic format at the end of the spring of 2008 to a stratified convenience sample of teachers in 60 schools within the district. In all, 941 teachers responded for a total response rate of $37 \%{ }^{1}$ The sample was stratified by school level and principal tenure, ${ }^{2}$ and all school identifiers were stripped from the dataset before it was released by the district. Of the 60 schools, 8 had response rates greater than $50 \%$ and 32 had response rates greater than $30 \%$. The schools' response rates ranged widely from 5 to $74 \%$. Post hoc focus groups suggested that the low overall response rate was at least in part due to the timing of the administration of the survey which was in late spring.

Teacher-level demographics were not available to the researchers beyond the grade range taught and whether or not the teacher held a leadership position in their school. Of the teachers responding to the survey, $33 \%$ taught pre-kindergarten through 6 th grade, $12 \%$ taught $7^{\text {th }}$ or $8^{\text {th }}$ grade, and $63 \%$ taught $9^{\text {th }}$ through $12^{\text {th }}$ grade. Leadership positions were held by $39 \%$ of the respondents (e.g., site council representative, union delegate, curriculum coordinator, lead teacher, department head, or other). Of the schools represented by responding teachers, $33 \%$ were elementary schools and $67 \%$ were middle and high schools. The data did not contain additional school characteristics.

\section{Measures}

\footnotetext{
${ }^{1}$ According to our district contact, district surveys typically have response rates of about $20 \%$.

${ }^{2}$ Principals were categorized as to whether or not they were new; $60 \%$ of the sampled schools were led by new principals.
} 
We selected scales of interest from the full Garvin, Edmondson, and Gino (2008) organizational learning survey tool and modified them for use in a school context. In particular, we examined three subscales sampling the constructs of psychological safety (PS), experimentation (EXP), and leadership that reinforces learning (LTRL). After a review of item content and cognitive pretesting (in which respondents talked through their thought processes as they read and answered each item), we modified items in the scales to sample these constructs making the language specific to schools (e.g., changed "unit" to "school") and clarified for respondents that the level of analysis was at the school level. We also eliminated a handful of items we anticipated would not function well in a school context. For example, from the original 5-item experimentation scale, we removed an item that read, "This unit frequently employs prototypes or simulations when trying out new ideas." (Garvin, Edmondson, \& Gino, 2008: 5). We also removed 2 items from the original 8-item leadership that reinforces learning scale that had to do with a leader's provision of resources, time, and money, whereas all other items in the scale involved leader behaviors that supported learning. Finally, we removed 2 psychological safety items that differed from other items in the original 5-item scale as they assessed actions rather than dispositions. The modified subscales piloted in this study were thus as follows:

- Psychological Safety (PS): This 3-item subscale from the OL building block, Supportive Learning Environment, measures on a 7-point response scale (7 = highest) whether teachers feel their school is a place where they can make mistakes and take the kinds of personal and intellectual risks that are necessary for continuous improvement. Teachers who felt psychologically safe indicated that people in their school were usually comfortable talking about problems and disagreements, that they were eager to share information about what does and doesn't work, and that mistakes were not be held against them.

- Experimentation (EXP): This 3-item subscale from the OL building block, Learning Processes and Practices, measures on a 7-point scale $(7=$ highest $)$ how teachers perceive the school's capacity for experimentation to achieve improvements. For example, items ask teachers if they feel within their schools that experimentation occurs frequently with new instructional practices or strategies, and/or there exists a 
formal process for conducting and evaluating experiments or new ideas.

- Leadership that Reinforces Learning (LTRL): This 6-item subscale measures the full Leadership building block and captures the extent to which principals' behavior communicates the support and value they place on learning. Teachers who responded with the highest rating $(7$ = highest) felt that their principal exemplified behaviors such as asking probing questions and acknowledging his or her own limitations with regard to knowledge, information, or expertise. ${ }^{3}$

\section{Procedures}

Prior to our use of the three subscales selected for this study, the full Garvin, Edmondson, and Gino (2008) organizational learning tool was subjected to two stages of field testing and refinement using 432 subjects in 4 separate populations to ensure the reliability and validity of the measures. Although the original field testing included two public sector organizations, neither were educational institutions, so we then reviewed and conducted cognitive testing with educational practitioners and researchers on the full original scales for psychological safety (PS), experimentation (EXP), and leadership that reinforces learning (LTRL) to assess the applicability of individual items to the school context. We made slight modifications to the language of items making them specific to school contexts and then embedded our items in a larger, pilot survey administered to teachers in a large, urban school district. Because all the items were drawn from a survey measuring organizational learning, we expected items and subscales to be highly correlated. However, our specific concern here is rather the dimensionality and underlying structure of organizational learning as captured in the subscales and their covariance. Thus we used confirmatory factor analysis (CFA) to confirm the structure of our factors, refine our scales, and examine how they related to the construct of organizational learning. Finally, we used path

${ }^{3}$ See Appendix A for the text of study measures. 
analysis to explore the directionality of any relationships confirmed in our data.

\section{Data Analyses}

Question 1: Are the subscales of psychological safety (PS), experimentation (EXP), and leadership that reinforces learning (LTRL) discrete subfactors of the second-order factor of organizational learning?

To begin, we examined the subscales of psychological safety, experimentation, and leadership that reinforces learning for their internal consistency reliability (Hatcher, 1994). Specifically, we examined descriptive statistics for each subscale, bivariate correlations among the individual items, and estimated the Cronbach’s alpha reliability statistics for the subscales.

Since much of the literature suggests multiple components to the secondary construct of organizational learning (OL) (e.g., Goh et al., 2006; Leithwood, Leonard, \& Sharratt, 1998; Silins et al., 2002), we then followed the procedures for confirmatory factor analysis described by Friendly (1995) and Kline (2005) to examine whether the subscales of psychological safety, experimentation, and leadership that reinforces learning are, indeed, discrete subfactors of the secondary factor of organizational learning. We fit a hypothetical model, as suggested by the Garvin, Edmondson, and Gino (2008) model (see Figure A) using the maximum likelihood method in the SAS system's CALIS procedure and examined three commonly used goodness-offit indices to determine model fit: the Root Mean Square Error of Approximation (RMSEA), Bentler’s Comparative Fit Index (Bentler, 1989), and the Bentler and Bonnet’s Non-Normed Fit Index (Bentler \& Bonnet, 1980; Hatcher, 1994; Kline, 1994; Kline, 2005). As recommended by Hatcher (1994), we identified poorly functioning items by examining residuals. We then examined the substance of the questions in order to determine if there was a substantive reason 
that might explain the poor fit prior to removal.

$<<$ Insert Figure A here $>>$

We refit the reduced model and examined factor loadings, correlations $\left(R^{2}\right)$, error terms, and $p$ values to confirm that our proposed hypothetical model was an appropriate description of the data.

Question 2: Are the subfactors (PS, EXP, LTRL) necessary intermediaries to organizational learning?

We again used CFA to investigate two alternative hypotheses: (1)whether the subfactors of psychological safety, experimentation, and leadership that reinforces learning are discrete factors that are important to the construct of organizational learning $\left(\mathrm{H}_{0}\right)$ or whether (2) there are no subfactors in the domain of organizational learning $\left(\mathrm{H}_{1}\right)$. As above, we fit hypothetical models (see Figure B) and examined fit to determine which rival hypothesis was confirmed by the data.

$<<<$ Insert Figure B here $>>>>$

Question 3: What is direction of the relationship between organizational learning and the subfactors of (psychological safety, experimentation, and leadership that reinforces learning)? Using CFA and path analysis, we examined two rival hypotheses (see Figure C) to 
determine the direction of the relationship between organizational learning and psychological safety, experimentation, and leadership that reinforces learning (PS, EXP, and LTRL). Specifically, we were interested in finding out whether the factors were expressions of organizational learning $\left(\mathrm{H}_{0}\right)$ or whether, in contrast they were determinants of organizational learning $\left(\mathrm{H}_{1}\right)$.

$<<<$ Insert Figure C here $>>>$

\section{Findings: Validation of Proposed Building Blocks of Organizational Learning}

Question 1: Are the subscales of psychological safety (PS), experimentation (EXP), and leadership that reinforces learning (LTRL) discrete subfactors of the second-order factor of organizational learning?

We first examined the internal consistency reliability of the organizational learning construct and its three hypothesized components of psychological safety, experimentation, and leadership that reinforces learning. In Table 1, Panels A-C, we display the item intercorrelations, the item means, and standard deviations for each of the three subscales of organizational learning. We also provide the estimated Cronbach’s alpha internal consistency reliability for each subscale. When we look at these descriptive statistics for each of the subscales, we note that each subscale appears to hang together as a construct and is thus an appropriate candidate for CFA.

$<<<<$ Insert Table 1, Panels A-C here $>>>$ 
As expected, the correlations between these subscales were high; ranging from .61, between experimentation (EXP) and leadership that reinforces learning (LTRL) to .85 between psychological safety (PS) and leadership that reinforces learning (LTRL). Our interest here, however, is the covariance between these subscales which gives us a better understanding of the underlying dimensionality of the larger construct of organizational learning. To this end, we used CFA to assess whether the three target subscales (PS, EXP, and LTRL) represent constructs that are captured by the second-order factor of organizational learning. We first fit a hypothetical model for the 3-item construct of psychological safety, the 3-item construct of experimentation, and the 6-item construct of leadership that reinforces learning. This model posits that each latent factor can be accurately estimated by including all items in the scale and accounting for their respective measurement errors (Hatcher, 1994). The hypothetical model failed to achieve good model fit.

Following the steps outlined in our procedures, we identified that one item in each of the experimentation (EXP) and leadership that reinforces learning (LTRL) scales had exceptionally large residuals. In addition to these problematic residuals, the third item in the experimentation subscale $^{4}$ differed substantively from the other two experimentation items in focusing on the existence of a process rather than on actual practices. Similarly, the $6^{\text {th }}$ item in the leadership that reinforces learning subscale ${ }^{5}$ also had problematic residuals and differed substantively from the remaining leadership that reinforces learning items. In this case, the reverse-coded item was the only one to attribute proactively negative behaviors to the principal. After removing these two items, we then refit the reduced model and confirmed that this final, proposed model accurately

\footnotetext{
${ }^{4}$ EXP3 -“This school has a formal process for conducting and evaluating experiments or new ideas.”

${ }^{5}$ LTRL6-“My principal criticizes views different from his or her own.”
} 
described our data.

This final reduced, fitted model contains three psychological safety items, two experimentation items, and five leadership that reinforces learning items. It met the threshold for an acceptable model fit based on three goodness-of-fit statistics. The RMSEA, which measures the "badness of fit," indicated an acceptable model fit with a value of .08 (where $<0.05$ indicates good fit and $<0.08$ indicates a fair fit) (Hatcher, 1994). The Bentler's Comparative Fit Index (CFI) of 0.98 and Bentler and Bonnet's Non-Normed Fit Index (NNFI) of 0.99 also indicated good fit (with good fit indicated by values exceeding 0.90 for both indices) (Hatcher, 1994).

Thus, as seen in Figure D, the final model fit indicates that psychological safety, experimentation, and leadership that reinforces learning are, indeed, discrete subfactors of the secondary factor of organizational learning. All estimated factor loadings and item error variances were statistically significant at the $p<0.0001$ level.

$<<$ insert Figure D here >>>

Given this final model, we calculated individual indicator reliability for each item and found these ranged from a low of .51 for the third item on the psychological safety subscale (PS3) to a high of .92 for the fifth item on the leadership that reinforces learning subscale (LTRL5). At the subscale level, psychological safety PS has a composite reliability of .83 but captures only $63 \%$ of the observed variance, largely due to low item reliability for both the second and third items in the scale (PS2 and PS3). Experimentation has a composite reliability of .86 and captures $75 \%$ of observed variance with individual reliabilities of .86 and .64 for the two items. Finally, leadership that reinforces learning (LTRL) has a composite reliability of .95 and 
captures $81 \%$ of observed variance with all individual items having strong individual reliabilities (see Table 2 below). Each of the subscales displays strong composite reliability indicating strong internal consistency reliability (R.B. Kline, 2005). Altogether, these findings support the internal reliability consistency of each of the three subscales of psychological safety, experimentation and leadership that reinforces learning (PS, EXP, and LTRL) with 3, 2, and 5 indicator variables respectively, as well as the second-order factor of organizational learning. $<<<$ insert Table 2 here $>>>$

Question 2: Are the subfactors of psychological safety, experimentation, and leadership that reinforces learning (PS, EXP, LTRL) necessary intermediaries to organizational learning (OL)?

To test whether the three factors of psychological safety, experimentation, and leadership that reinforces learning (PS, EXP, and LTRL) were necessary intermediaries to the second-order factor of OL, we tested two rival, hypothesized models which describe two possible relationships between OL and the indicators of teacher perceptions of OL. The rival hypotheses were constructed to follow CFA procedures for testing moderation or mediation of the intermediate constructs on overall OL (Kline, 2005). The first model $\left(\mathrm{H}_{0}\right.$ in Figure E) proposes that OL is an underlying condition which is expressed by teacher perceptions of the subfactors of psychological safety, experimentation, and leadership that reinforces learning.

This hypothesized model met the threshold for acceptable model fit based on three goodness-of-fit statistics. Specifically, the RMSEA indicated an acceptable model fit with a value of .08. Finally, the Bentler’s Comparative Fit Index (CFI) of 0.98 and Bentler and Bonnet's Non-Normed Fit Index (NNFI) of 0.98 also indicate good fit (Hatcher, 1994). 
In contrast, our rival model posited that the relationships between OL and the indicators of teacher perceptions were direct and not moderated by the subfactors of psychological safety, experimentation, and leadership that reinforces learning (PS, EXP, and LTRL). However, we reject this model based on poor fit statistics $(\mathrm{RMSEA}=0.17, \mathrm{CFI}=0.880, \mathrm{NNFI}=0.85)$. We, thereby, conclude that the three subfactors of psychological safety, experimentation, and leadership that reinforces learning are necessary mediating factors within the second-order construct of organizational learning (as shown in Figure E).

$<<$ insert figure E here >>>

Question 3: What is direction of the relationship between organizational learning and the subfactors of psychological safety, experimentation, and leadership that reinforces learning?

Despite the plethora of research on OL, there is little empirical evidence regarding the directionality of the relationship between overall organizational learning and its subcomponents. Thus, for our final set of analyses, we used CFA to examine the pathway between OL and the three subfactors of psychological safety, experimentation, and leadership that reinforces learning (PS, EXP, and LTRL), in order to determine the direction of this relationship. We examined and fit two rival hypotheses to determine whether the factors were expressions of organizational learning or whether, in contrast, they were determinants of organizational learning.

Our first hypothesized model $\left(\mathrm{H}_{0}\right.$ in Figure $\left.\mathrm{F}\right)$ proposes that $\mathrm{OL}$ is an underlying construct or condition that expresses itself through the subfactors of psychological safety, experimentation, and leadership that reinforces learning. Based on the fit statistics for this model, we confirmed this hypothesis. Specifically, the RMSEA, which measures the "badness of fit," 
indicated an acceptable model fit with a value of .08 (Hatcher, 1994). Bentler's Comparative Fit Index (CFI) of 0.98 and Bentler and Bonnet’s Non-Normed Fit Index (NNFI) of 0.98 also indicate good fit (Hatcher, 1994).

Our rival model $\left(\mathrm{H}_{1}\right.$ in Figure $\left.\mathrm{F}\right)$ hypothesized that teacher perceptions of psychological safety, experimentation, and leadership that reinforces learning predict levels of organizational learning. The fit statistics for this model suggest that this model fits the data poorly: RMSEA = 0.22 , CFI $=0.83$, NNFI $=0.75$. We, thereby, conclude that the observed levels of the indicators of psychological safety, experimentation, and leadership that reinforces learning subfactors are measurable expressions or manifestations of the second-order construct of organizational learning.

$<<$ insert figure $\mathrm{F}$ here $>>>$

\section{Discussion}

The goal of the present research was to investigate the merits of drawing upon and applying organizational learning theory and methods from the field of organizational behavior to better understand organizational learning in schools. We investigated these both conceptually and empirically. From a conceptual perspective, our review of the OL literature pointed toward a need for better integration between two parallel streams of OL research: a cognitive stream that has emphasized individuals' abilities to search, process, store, and manage information and a sociocultural stream that has emphasized the social relationships and practices in which learning is embedded. As education scholars suggested, the OL literature in education has become bifurcated, which has undermined research progress on organizational reform.

To answer this call for integration in the literature, we drew specifically upon the work of 
Garvin, Edmondson, and Gino (2008) who published an organizational learning tool for practitioners but whose dimensions had not yet been tested or adapted, and for our purposes, we applied it to the context of education. By introducing specific constructs from organizational behavior theory such as "psychological safety" (Edmondson, 1999), experimentation, and leadership that reinforces learning, we provide new ways of describing and also studying the learning environment for adults, specifically teachers, in schools. Rather than presenting these constructs as a comprehensive tool, we see these measures as augmenting the existing instruments and scales in the growing literature on organizational learning in schools, and we present them as an integrated conceptualization of key aspects of OL.

Using confirmatory factor analyses, we were able to validate three subscales for use assessing levels of psychological safety, experimentation, and leadership that reinforces learning. We were also able to confirm that even though each of these constructs captures a different and necessary dimension of organizational learning, they are all explained by the second-order factor of organizational learning. For practical purposes, the discrete nature of the subscales suggests that organizational learning is indeed a multifaceted construct. As Garvin and colleagues suggest, there are discrete dimensions within the domain of organizational learning: "Each block and its discrete subcomponents, though vital to the whole, are independent and can be measured separately” (Garvin, Edmondson, \& Gino, 2008, p. 2). We cannot sample one dimension (e.g., experimentation) and assume that we have adequately sampled the global construct of organizational learning, nor can we generalize about levels of organizational learning from observed levels of one discrete dimension. Rather, the subscales considered simultaneously and in an integrated way describe the overall construct of organizational learning. In this case, we found that the quality of a school's organizational learning is best understood by considering our 
three subscales jointly.

We also found that the second-order factor of organizational learning predicts levels of psychological safety, experimentation, and leadership that reinforces learning. In other words, in schools with strong organizational learning cultures, teachers are more likely to report higher levels of psychological safety, experimentation, and leadership that reinforces learning. Although future research is warranted, our analyses suggest, therefore, that rather than using the subscales to sample preconditions of organizational learning, we may be able to use these scales to better understand the dimensionality of organizational learning in different contexts. Prior research has suggested that "building blocks of organizational learning reinforce each other” (Garvin, Edmondson, \& Gino, 2008, p. 5), but this is the first empirical test of the directionality of these relationships.

One way to think about the practical significance of our findings is to consider hypothetical examples of how these subcomponents might or might not relate to one another in practice. Our findings suggest that only addressing one dimension of organizational learning may not lead to higher levels of organizational learning. Indeed, one possible interpretation of the analysis is that efforts to increase levels of organizational learning cannot do so in a piecemeal way by focusing on one or another of the dimensions of organizational learning. For example, consider a hypothetical faculty meeting in which the principal acknowledges the limitations of her own knowledge and seeks input and direction from the group. However, suppose the teachers in her school, for whatever historical and/or external reason, don't feel eager to share what works and does not work and as a faculty, have no habit of experimenting with new ways of working In this context, the principal's exercise of leadership behaviors that support learning might not be a good measure of organizational learning in the school as a 
whole.

Rather, achieving higher levels of organizational learning may necessitate paying attention to several dimensions of organizational learning concurrently. To return to our prior example, in this hypothetical school, the organization has relatively high levels of leadership that reinforce learning, but the staff feels unsafe and has little experience with experimentation. In order to improve organizational learning, our findings suggest that the principal - who already leads in ways that reinforce learning - might also need to attend to strategies that address psychological safety and experimentation. She might examine these aspects of the climate further and follow up with opportunities for pair and share conversations, anonymous feedback, and teacher-coach assisted experimentation. However, interventions that might be appropriate for this school are potentially very different from possible interventions for a school with similar, overall reported levels of organizational learning but in which teachers report high levels of psychological safety yet low levels of experimentation and leadership that reinforce learning - a context that perhaps suggests complacency.

As Garvin and colleagues imply, multiple building blocks are "vital to the whole," (Garvin, Edmondson, \& Gino, 2008, p. 2); they are essential to building an overarching organizational learning environment. This parts/whole perspective jibes nicely with recent research on school reform by Bryk and colleagues (2010) who liken reform to baking a cake in which five essential ingredients - including creating an effective school learning climate for teachers - must all be included. Here, we offer specific constructs that we hope will complement the existing literature in enabling scholars and practitioners alike to measure several key facets of organizational learning and consider their implications for school improvement. 


\section{Study Limitations and Implications for Future Research}

Of course, this study is not without limitations. Future research conducted with a larger sample, a higher response rate, and the inclusion of other scales to conduct correlational analyses to test convergent and divergent validity would allow us to investigate further whether the relationships originally proposed by Garvin and colleagues (2008) among these OL building blocks of organizational learning perform as theory and prior research would suggest. Moreover, teachers in high schools were overrepresented in our sample compared to those in elementary schools. Organizational and cultural differences between elementary and comprehensive high school settings may contribute to different understandings of constructs like "psychological safety" and "organizational learning" in these two contexts—a difference that could be untangled in further research. Such analyses would provide greater validity for the use of these measures and the instrument introduced by Garvin and colleagues employed here.

Secondly, this validation study suggests the need for additional development, refinement, and field testing of items that sample key dimensions of organizational learning. For example, experimentation was reduced to only two items and in its modified form, had a relatively high level of error which indicates that it is a weak measure. Substantively, a reasonable explanation for this may be that in school settings, the word "experimentation" has different connotations than it does in other sectors. Moreover, because control over curriculum and instruction is increasingly centralized in this particular school system and in other similar large urban school systems, teachers may be less likely to associate "experimentation" at the school level as a positive component of organizational learning. The weakness of the measure may also be related to the substantive changes required for the best overall model fit; the two retained items related to the frequency of experimentation while the third item (which was eliminated) related to 
monitoring or evaluating the results of experimentation. Examining data on additional measures of organizational learning focused on this construct within a different district context, and using different, less loaded terms might better inform our understanding of the construct of experimentation and/or innovation in school settings. Such analyses might also further our ability to extend and build upon recent education research on innovation (e.g., Moolenaar, Daly, \& Sleegers, in press).

Third, lacking access to demographic and socioeconomic data or disaggregated data on student performance linked to the schools in this study, we were also limited in our ability to examine relationships between specific school contexts and observed levels of organizational capacity beyond those reported. For example, although we found that teachers in some schools felt, on average, more psychologically safe than teachers in other schools, the limitations of our data prevent us from exploring whether these teachers differ from their colleagues in some substantive ways making them less likely, for example, to fear being penalized for their mistakes. It also limited us on assessing whether those schools differ in systematic ways from other schools.

Finally, we cannot draw conclusions about what leads to the reported levels of organizational capacity that we observed in these data. Without longitudinal data that links teacher and school responses over time, we cannot investigate causal links between various teacher and school-level characteristics such as access to and availability of resources and the levels of organizational learning in those schools. Future research that examines these constructs longitudinally along with some clear outcome indicators would strengthen our understanding of “organizational capacity,” especially if such quantitative data were coupled with qualitative research. For example, insights into the actual behaviors that teachers engage in when 
“experimenting” would help us better understand if and how reported levels of

"experimentation" match with actual changes in instructional practice in the classroom in schools.

\section{Conclusion}

This study suggests that a more theoretically integrated understanding of organizational learning in schools has much to offer efforts to improve instruction and enhance student achievement systemwide. By taking a conceptually integrated stance and empirically testing an organizational learning instrument in a large urban district, this research contributes to our knowledge of how, from the perspective of teachers, organizational learning is manifest at a school site. In this way, our work builds upon seminal research on the social context in which teachers work (e.g., McLaughlin, Talbert, \& Bascia, 1990) and aligns with contemporary research on organizational learning in school systems as well (e.g., Bryk et al., 2010). In particular, the modified scales of psychological safety, experimentation, and leadership that reinforces learning provide a nuanced tool for examining the key organizational climate, practices and processes, and leadership within which collective learning takes place. Our findings not only reaffirm the notion that effective school change processes must go beyond new programs and structures and attend to the overall culture for capacity building, they also suggest that piecemeal interventions that address isolated elements of organizational learning may be insufficient for refashioning schools into "learning organizations."

At the same time, we note that organizational learning may be but one element in the equation for high performance. As organizational scholars have recently suggested, high performance is most likely achieved when organizations feel a strong sense of accountability (or 
shared responsibility) for creating positive outcomes (Edmondson, 2008). In the context of school systems design, education scholars contend that the accountability of local professionals to educate and support every child and his or her caretakers is paramount to improving performance (Bryk et al., 2010). At the local level, then, the ideal school may possibly be one in which teachers feel psychologically safe to speak up and ask for help and are motivated to do so by their shared responsibility or accountability for high-quality teaching and learning. As Edmondson (2008) argues, an environment in which people feel psychologically safe but not accountable is one in which there is apt to be complacency, whereas an environment in which one feels accountable but not psychologically safe is one in which individuals are less likely to take risks or engage in the kind of transformational learning many experts deem necessary to improve schools today. In isolation, the constructs of psychological safety and experimentation cannot definitively diagnose the condition of an individual school's organizational culture, but findings based on these scales can point educators and researchers towards aspects of school culture that need further exploration. That said, future researchers can build upon our work by examining OL differences across schools including observed differences in reported levels of psychological safety and experimentation. Moreover, researchers can clarify the relationship between these constructs and various teacher and school characteristics including teacher experience and teacher learning orientation as well as teachers' collective efficacy and shared accountability for student learning. 
Appendix A: Items in the Scales

Indicators in the initial, hypothesized subscales of organizational learning

Items in the psychological safety (PS) subscale:

1) In this school, it is easy to speak up about what is on your mind.

2) People in this school are usually comfortable talking about problems and disagreements.

3) People in this school are eager to share information about what does and doesn't work.

Items in the experimentation (EXP) subscale:

1) This school experiments frequently with new ways of working.

2) This school experiments frequently with new instructional practices or strategies.

3) This school has a formal process for conducting and evaluating experiments or new ideas.

Items in the leadership that reinforces learning (LTRL) subscale:

1) My principal invites input from others in discussions.

2) My principal acknowledges his or her own limitations with respect to knowledge, information, or expertise.

3) My principal asks probing questions.

4) My principal listens attentively.

5) My principal encourages multiple points of view.

6) My principal criticizes views different from his or her own. (reverse coded item) 


\section{References}

Boyd, W. L. (Ed.). (2008). American Journal of Education (2008), 114 (4).

Argyris, C., \& Schon, D. A. (1996). Organizational learning II: Theory, methods and practice. Reading, MA: Addison-Wesley.

Bentler, P. M. (1989). Causal modeling via structural equation systems. In J. R. Nesselroade \& R. B. Cattell (Eds.), Handbook of multivariate experimental psychology: Perspectives on individual difference (2nd ed., pp. 317-335). New York: Plenum Press.

Bentler, P. M., \& Bonett, D. G. (1980). Significance tests and goodness of fit in the analysis of covariance structures. Psychological Bulletin, 88, 588-606.

Boudett, K. P., City, E. A., \& Murnane, R. J. (Eds.). (2005). Data wise: A step-by-step guide to using assessment results to improve teaching and learning. Cambridge, MA: Harvard Education Press.

Bryk, A. S., Camburn, E., \& Louis, K. S. (1999). Professional community in Chicago elementary schools: Facilitating factors and organizational consequences. Educational Administration Quarterly, 35(5), 751-781.

Bryk, A. S., \& Schneider, B. (2003). Trust in schools: A core resource for school reform. Educational Leadership, 60(6), 40-44.

Bryk, A. S., Sebring, P. E., Allensworth, A. L., \& Easton, J. Q. (2010). Organizing schools for improvement: Lessons from Chicago. Chicago: University of Chicago Press. 
Chicago Consortium for School Research. (n.d.). Items that compose the measure innovation. Retrieved from http://ccsr.uchicago.edu/surveymeasures2007/innv.html

Cohen, D. (1990). A revolution in one classroom: The case of Mrs. Oublier. Educational Evaluation and Policy Analysis, 12(3), 311-329.

Cohen, W., \& Levinthal, D. (1990). Absorptive capacity: A new perspective on learning and innovation. Administrative Science Quarterly, 35(1), 128-152.

Cole, M., \& Wertsch, J. V. (1996). Beyond the individual-social antinomy in discussions of Piaget and Vygotsky. Human Development, 39(5), 250-256.

Collinson, V., Cook, T., \& Conley, S. (2006). Organizational learning in schools and school systems: Improving learning, teaching, and leading. Theory into Practice, 45(2), 107-116.

Copland, M. A., \& Knapp, M. S. (2006). Connecting leadership with learning: A framework for reflection, planning, and action. Alexandria, VA: Association for Supervision and Curriculum Development.

Cousins, J. B. (1996). Understanding organizational learning for educational leadership and school reform. In K. Leithwood, J. Chapman, P. Corson, P. Hallinger, \& A. Hart (Eds.), International handbook of educational leadership and administration (pp. 589-652). Dordrecht, The Netherlands: Kluwer Academic.

Darling-Hammond, L. (1996). What matters most: A competent teacher for every child. Phi Delta Kappan, 78(3), 193-200. 
Edmondson, A. C. (1999). Psychological safety and learning behavior in work teams. Administrative Science Quarterly, 44(2), 350-383.

Edmondson, A. C. (2003). Speaking up in the operating room: How team leaders promote learning in interdisciplinary action teams. Journal of Management Studies, 40(6), 14191452.

Edmondson, A. C. (2008). The competitive imperative of learning. Harvard Business Review, 86(7), 60-67.

Elmore, R. F. (2002). Unwarranted intrusion. Education Next, 2(1), 30-35.

Friendly, M. (1995). Planning a factor analytic study. Retrieved from http://www.psych.yorku.ca/lab/psy6140/fa/facplan.htm

Fullan, M. (1995). The school as learning organization: Distant dreams. Theory into Practice, 34(4), 230-235.

Gallucci, C. (2008). Districtwide instructional reform: Using sociocultural theory to link professional learning to organizational support. American Journal of Education, 114(4), 541-581.

Garvin, D. A., Edmondson, A. C., \& Gino, F. (2008). Is yours a learning organization? Harvard Business Review, 86(3), 109-116. 
Giles, C., \& Hargreaves, A. (2006). The sustainability of innovative schools as learning organizations and professional learning communities during standardized reform. Educational Administration Quarterly, 42(1), 124-156.

Goh, S., Cousins, J., \& Elliott, C. (2006). Organizational learning capacity, evaluative inquiry and readiness for change in schools: Views and perceptions of educators. Journal of Educational Change, 7(4), 289-318.

Goh, S., \& Richards, G. (1997). Benchmarking the learning capability of organizations. European Management Journal, 15(5), 575-583.

Hatcher, L. (1994). A step-by-step approach to using the SAS system for factor analysis and structural equation modeling. Cary, NC: SAS Institute.

Honig, M. I. (2004). Where’s the ‘up’ in bottom-up reform? Educational Policy, 18(4), 527-561.

Honig, M. I. (2008). District central offices as learning organizations: How sociocultural and organizational learning theories elaborate district central office administrators' participation in teaching and learning improvement efforts. American Journal of Education, 114(4), 627664.

Hopkins, D., Harris, A., \& Jackson, D. (1997). Understanding the school’s capacity for development: Growth states and strategies. School Leadership \& Management, 17(3), 401411.

Hord, S. (1997). Professional learning communities: Communities of continuous inquiry and improvement. Austin, TX: Southwest Educational Development Lab. 
Hubbard, L., Mehan, H., \& Stein, M. K. (2006). Reform as learning: When school reform collides with school culture and community politics. New York: Routledge.

Huber, G. P. (1991). Organizational learning: The contributing processes and the literatures. Organization Science, 2(1), 88-115.

Imants, J. (2003). Two basic mechanisms for organisational learning in schools. European Journal of Teacher Education, 26(3), 293-311.

Johnson, S. M. (1996). Leading change: The challenge of the new superintendency. San Francisco: Jossey Bass.

Kline, P. (1994). An easy guide to factor analysis. New York: Routledge.

Kline, R. B. (2005). Principles and practice of structural equation modeling (2nd ed.). New York: Guilford Press.

Knapp, M. (2008). How can organizational and sociocultural learning theories shed light on district instructional reform? American Journal of Education, 114(4), 521-539.

Leithwood, K., \& Aitken, R. (1995). Making schools smarter: A system for monitoring school and district progress. Thousand Oaks, CA: Corwin.

Leithwood, K., \& Jantzi, D. (2006). Transformational school leadership for large-scale reform: Effects on students, teachers, and their classroom practices. School Effectiveness and School Improvement, 17(2), 201-227. 
Leithwood, K., Leonard, L., \& Sharratt, L. (1998). Conditions fostering organizational learning in schools. Educational Administration Quarterly, 34(2), 243-276.

Levinthal, D. A., \& March, J. G. (1993). The myopia of learning. Strategic Management Journal, 14, 95-112.

Levitt, B., \& March, J. G. (1988). Organizational learning. Annual Review of Sociology, 14, 319340.

Louis, K. S., Marks, H. M., \& Kruse, S. (1996). Teachers' professional community in restructuring schools. American Educational Research Journal, 33(4), 757-798.

March, J. G., \& Simon, H. A. (1958). Organizations. New York: John Wiley \& Sons.

Marks, H. M., \& Louis, K. S. (1999). Teacher empowerment and the capacity for organizational learning. Educational Administration Quarterly, 35(5), 707-750.

McLaughlin, M. W., \& Talbert, J. E. (2006). Building school-based teacher learning communities. New York: Teachers College Press.

McLaulghlin, M. W., Talbert, J. E., \& Bascia, N. (1990). The contexts of teaching in secondary schools: Teachers’ realities. New York: Teachers College Press.

Moolenaar, N. M., Daly, A. J., \& Sleegers, P. J. C. (in press). Ties with potential: Social network structure and innovative climate in Dutch schools. Teachers College Record. 
Porter, A., Polikoff, M., Goldring, E., Murphy, J., Elliott, S., \& May, H. (2010). Developing a psychometrically sound assessment of school leadership: The VAL-ED as a case study. Educational Administration Quarterly, 46(2), 135-173.

Schechter, C. (2008). Organizational learning mechanisms: The meaning, measure, and implications for school improvement. Educational Administration Quarterly, 44(2), 155186.

Senge, P. M. (1990). The fifth dimension: The art and practice of the learning organization. New York: Doubleday.

Silins, H. C., Mulford, W. R., \& Zarins, S. (2002). Organizational learning and school change. Educational Administration Quarterly, 38(5), 613-642.

Stein, M., \& Coburn, C. (2008). Architectures for learning: A comparative analysis of two urban school districts. American Journal of Education, 114(4), 583-626.

Stoll, L. (1999). Realising our potential: Understanding and developing capacity for lasting improvement. School Effectiveness and School Improvement, 10(4), 503-532.

Stoll, L. (2009). Capacity building for school improvement or creating capacity for learning? A changing landscape. Journal of Educational Change, 10(2/3), 115-127.

Stoll, L., Bolam, R., McMahon, A., Wallace, M., \& Thomas, S. (2006). Professional learning communities: A review of the literature. Journal of Educational Change, 7(4), 221-258. 
Van de Ven, D., \& Polley, A. (1992). Learning while innovating. Organization Science, 3(1), 92116.

Vygotsky, L. S. (1978). Mind in society: The development of higher psychological processes (M. Cole, V. John-Steiner, S. Scribner, \& E. Souberman, Eds.). Cambridge, MA: Harvard University Press.

Wertsch, J. V. (1996). A sociocultural approach to socially shared cognition. In L. B. Resnick, J. M. Levine, \& S. D. Teasley (Eds.), Perspectives on socially shared cognition (pp. 85-100). Hyattsville, MD: American Psychological Association. 
Figure A: Hypothetical model of the relationship between the three subscales of psychological safety (PS), experimentation (EXP), and leadership that reinforces learning (LTRL) and the hypothesized second-order factor of organizational learning.

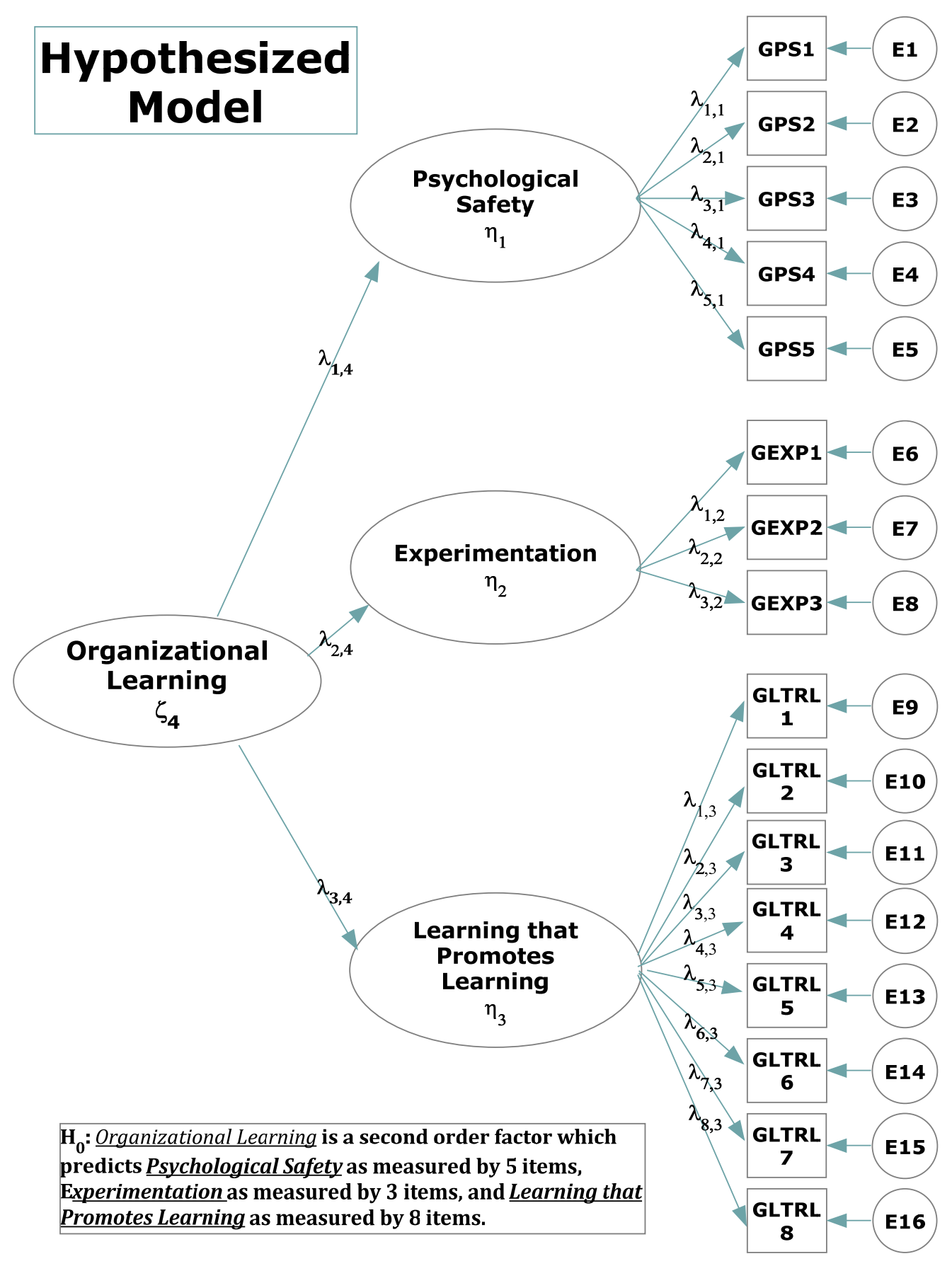


Figure B: Rival hypothetical models to test whether the subfactors (PS, EXP, and LTRL) are necessary intermediaries to OL

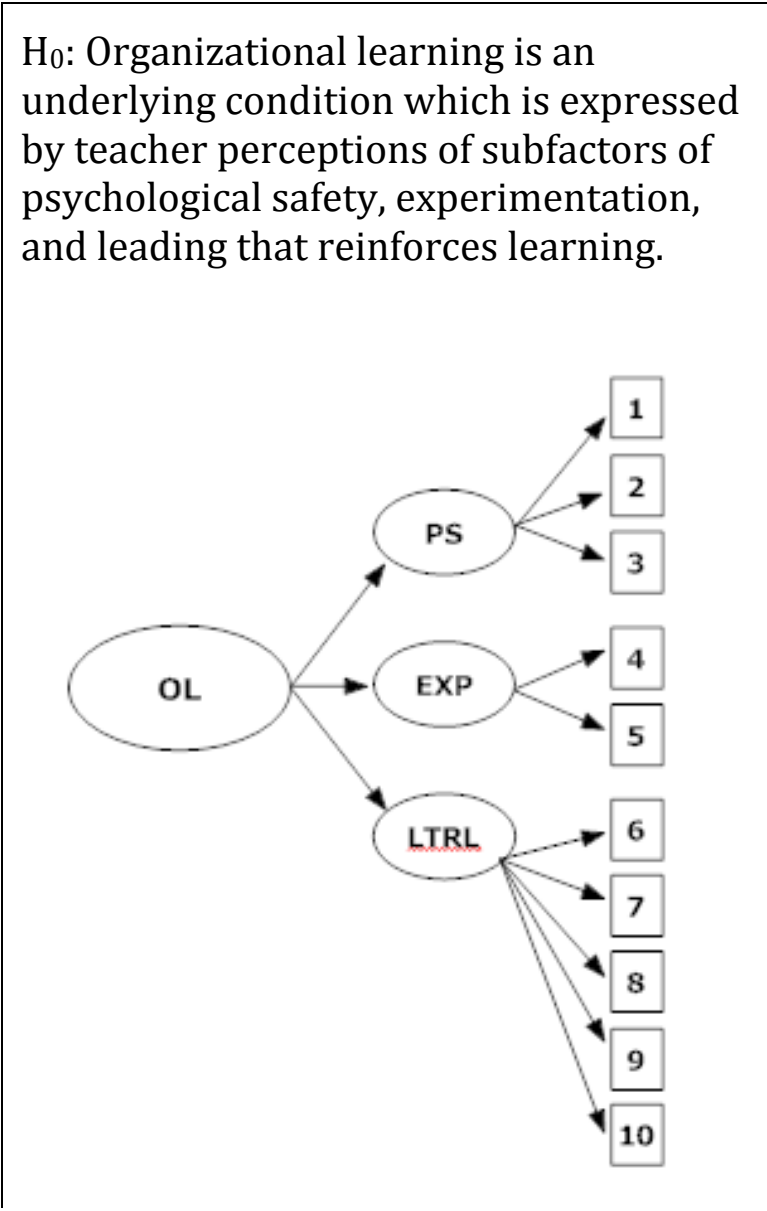

$\mathrm{H}_{1}$ : Organizational learning is an underlying condition which is expressed by teacher perceptions, but there are no subfactors within this larger domain.

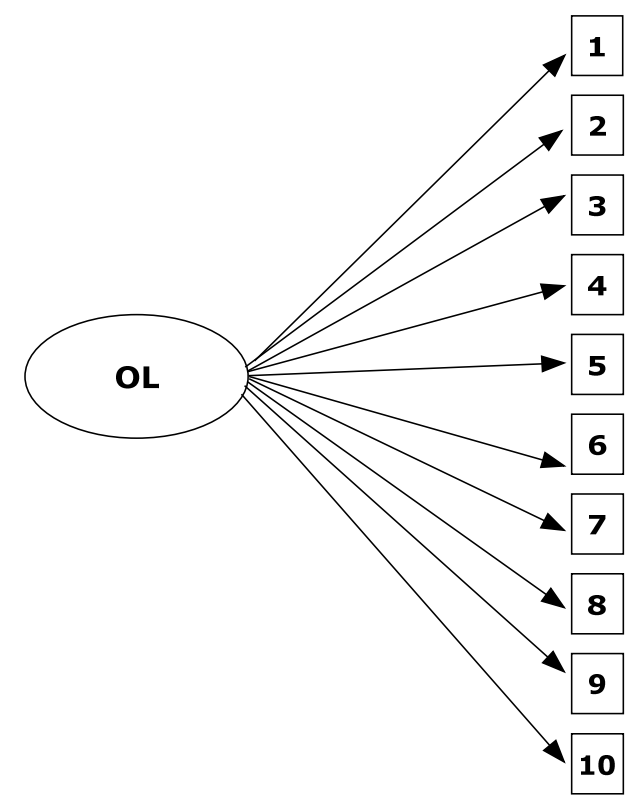


Figure C: Rival hypothetical models to test the directionality of the relationship between subfactors (PS, EXP, and LTRL) and the second-order construct of organizational learning (OL).

\begin{tabular}{|l|l|}
$\begin{array}{l}\mathrm{H}_{0} \text { : Organizational learning is an underlying } \\
\text { condition which is expressed by teacher } \\
\text { perceptions of psychological safety, } \\
\text { experimentation, and leading that } \\
\text { reinforces learning. }\end{array}$ & $\begin{array}{l}\mathrm{H}_{1} \text { : Teacher perceptions of psychological } \\
\text { safety, experimentation, and leading that } \\
\text { reinforces learning are determinants of } \\
\text { organizational learning. }\end{array}$
\end{tabular}


Figure D: Final fitted model of the relationship between the three subscales of psychological safety (PS), experimentation (EXP), and leadership that reinforces learning (LTRL) and the hypothesized second-order factor of organizational learning.

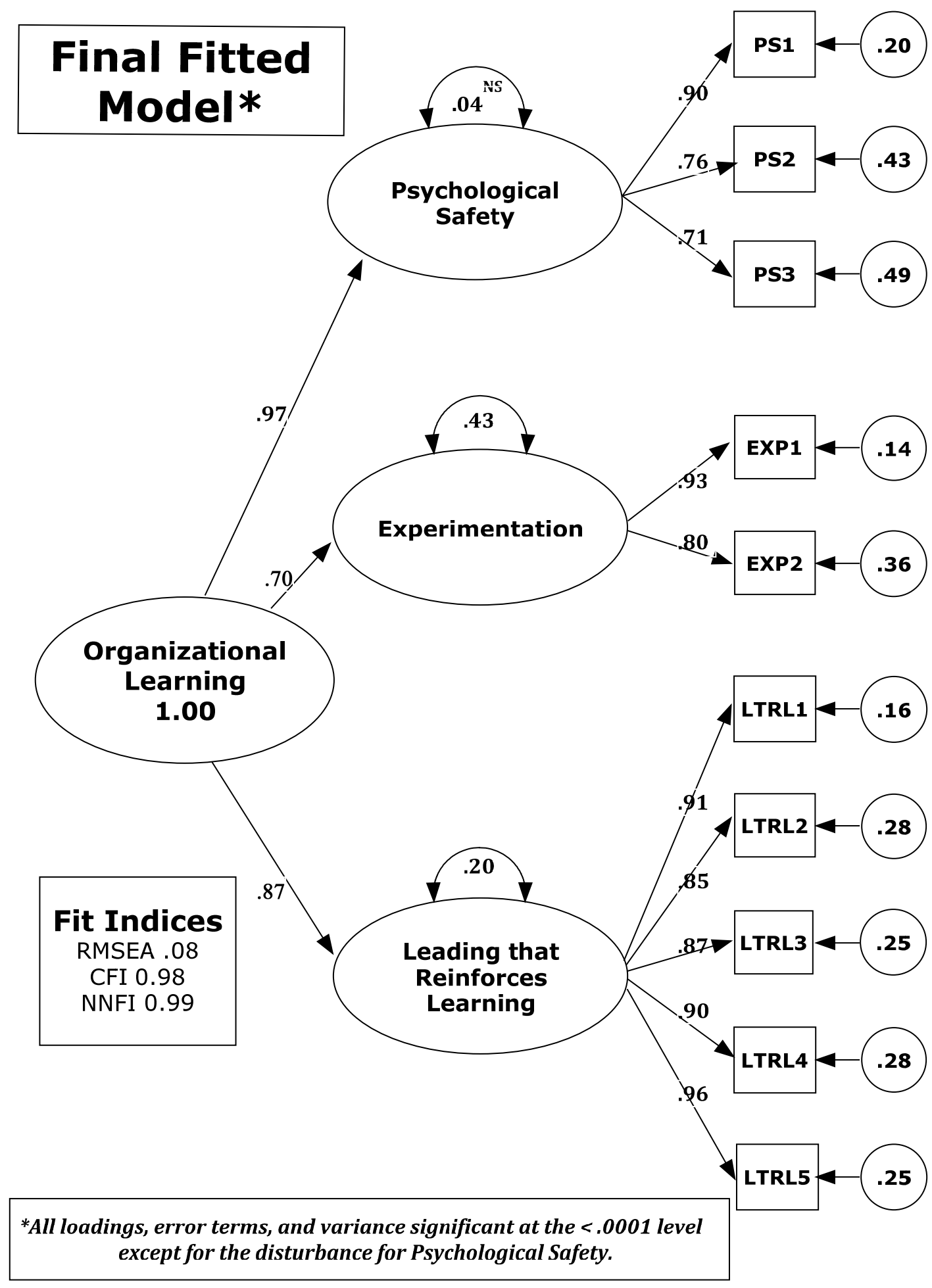


Figure E: Figure showing rival hypotheses regarding the relationship between the secondorder factor of OL and the indicators of organizational learning (items).

$\mathrm{H}_{0}$ : Organizational learning is an underlying condition which is expressed by teacher perceptions of subfactors of psychological safety, experimentation, and leading that reinforces learning.

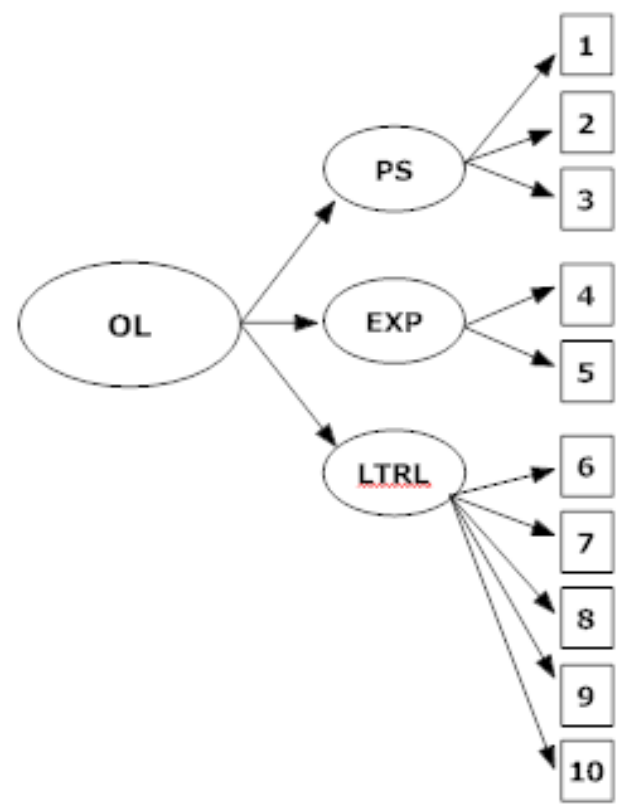

$\mathrm{X}_{2}$ Statistic $=199.64$

$$
d f=29
$$

$$
\text { RMSEA }=.08
$$

Bentler's CFI $=.98$

Bentler \& Bonett's NNFI $=.98$

Hypothesis confirmed
$\mathrm{H}_{1}$ : Organizational learning is an underlying condition which is expressed by teacher perceptions, but there are no subfactors within this larger domain.

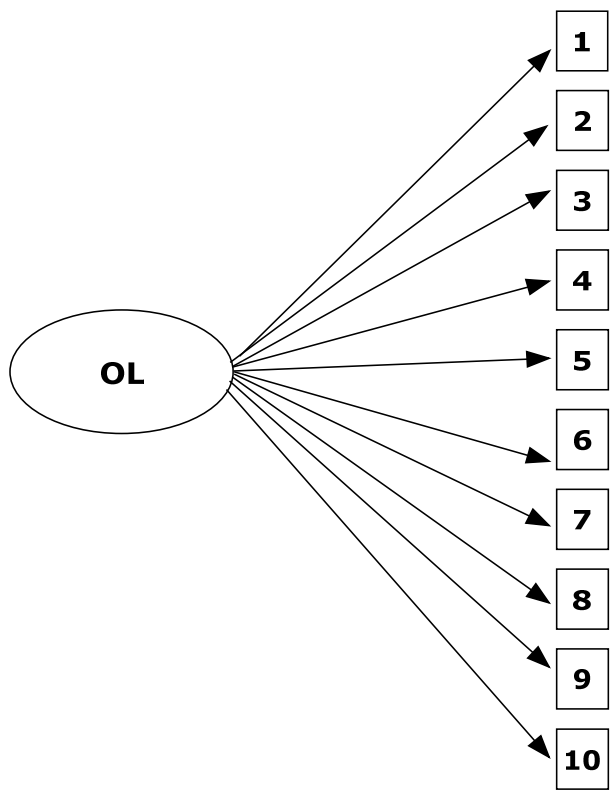

$\mathrm{X}_{2}$ Statistic $=1002.01$

$$
d f=35
$$

$$
\text { RMSEA }=.17
$$

Bentler's CFI $=.88$

Bentler \& Bonett's NNFI $=.85$

Hypothesis rejected 
Figure F: Figure showing rival hypotheses regarding the directionality of the relationship between organizational learning and the indicators used to sample this domain.

\begin{tabular}{|l|l|}
$\begin{array}{l}\mathrm{H}_{1} \text { : Organizational learning is an underlying } \\
\text { condition which is expressed by teacher } \\
\text { perceptions of psychological safety, } \\
\text { experimentation, and leading that reinforces } \\
\text { learning. }\end{array}$ & $\begin{array}{l}\mathrm{H}_{2} \text { : Teacher perceptions of psychological } \\
\text { safety, experimentation, and leading that } \\
\text { reinforces learning are determinants of } \\
\text { organizational learning. }\end{array}$ \\
\hline $\begin{array}{c}\text { Organizational } \\
\text { Learning }\end{array}$ \\
$\begin{array}{c}\text { Leading that } \\
\text { Reinforces } \\
\text { Searning }\end{array}$
\end{tabular}


Table 1, Panels A-C: Tables showing the within subscale item correlations, item means, and item standard deviations for psychological safety (PS), experimentation (EXP), and leadership that reinforces learning (LTRL)

Panel A: Psychological Safety

\begin{tabular}{cllc}
\hline Indicators & PS1 & \multicolumn{1}{c}{ PS2 } & PS3 \\
\hline PS1 & 1.00 & & \\
PS2 & $0.66^{* * *}$ & 1.00 & \\
PS3 & $0.61^{* * *}$ & $0.64^{* * *}$ & 1.00 \\
\hline Chronbach Coefficient Alpha $=.83$ & & & \\
\hline Mean & 4.69 & 4.56 & 5.31 \\
SD & 2.06 & 1.86 & 1.63 \\
\hline
\end{tabular}

$\mathrm{N}=933$

Panel B: Experimentation

\begin{tabular}{|c|c|c|c|c|c|c|}
\hline Indicators & & & EXP1 & EXP2 & & EXP3 \\
\hline EXP1 & & & 1.00 & & & \\
\hline EXP2 & & & $0.74 * * *$ & 1.00 & & \\
\hline EXP3 & & & $0.49 * * *$ & $0.45^{* * *}$ & & 1.00 \\
\hline \multicolumn{7}{|c|}{ Chronbach Coefficient Alpha $=.79$} \\
\hline Mean & & & 4.83 & 5.00 & & 3.95 \\
\hline SD & & & 1.65 & 1.63 & & 1.83 \\
\hline \multicolumn{7}{|l|}{$\mathrm{N}=922$} \\
\hline \multicolumn{7}{|c|}{ Panel C: Leadership That Reinforces Learning } \\
\hline Indicators & LTRL1 & LTRL2 & LTRL3 & LTRL4 & LTRL5 & LTRL6 \\
\hline LTRL1 & 1.00 & & & & & \\
\hline LTRL2 & $0.78^{* * *}$ & 1.00 & & & & \\
\hline LTRL3 & $0.79 * * *$ & $0.75 * * *$ & 1.00 & & & \\
\hline
\end{tabular}




\begin{tabular}{ccccccc} 
LTRL4 & $0.80 * * *$ & $0.77^{* * *}$ & $0.79 * * *$ & 1.00 & & \\
LTRL5 & $0.88^{* * *}$ & $0.80^{* * *}$ & $0.82 * * *$ & $0.86 * * *$ & 1.00 & \\
LTRL6 & $0.50^{* * *}$ & $0.51^{* * *}$ & $0.46 * * *$ & $0.52 * * *$ & $0.55^{* * *}$ & 1.00 \\
\hline Chronbach Coefficient Alpha $=.79$ & & & & & \\
\hline Mean & 5.20 & 4.91 & 5.01 & 5.12 & 4.95 & 4.61 \\
SD & 1.92 & 1.98 & 1.89 & 1.99 & 2.02 & 2.02 \\
\hline $\mathrm{N}=914$ & & & & & &
\end{tabular}


Table 2: Table showing the loadings and the estimated composite reliability indices for each of the subscales and the second-order factor of organizational learning in our final, fitted model.

\begin{tabular}{|c|c|c|c|c|c|}
\hline $\begin{array}{l}\text { Construct and } \\
\text { Indicators }\end{array}$ & $\begin{array}{l}\text { Standardized } \\
\text { Loading }\end{array}$ & $\begin{array}{c}\text { Indicator } \\
\text { Reliability* }\end{array}$ & $\begin{array}{c}\text { Error } \\
\text { Variance* }\end{array}$ & $\begin{array}{l}\text { Composite } \\
\text { Reliability }\end{array}$ & $\begin{array}{l}\text { Variance } \\
\text { Extracted }\end{array}$ \\
\hline \multicolumn{2}{|c|}{ Psychological Safety } & & & 0.83 & 0.63 \\
\hline PS1 & 0.90 & 0.80 & 0.20 & & \\
\hline PS2 & 0.76 & 0.57 & 0.43 & & \\
\hline PS3 & 0.71 & 0.51 & 0.49 & & \\
\hline \multicolumn{2}{|c|}{ Experimentation } & & & 0.86 & 0.75 \\
\hline EXP1 & 0.93 & 0.86 & 0.14 & & \\
\hline EXP2 & 0.80 & 0.64 & 0.36 & & \\
\hline \multicolumn{3}{|c|}{ Leading That Reinforces Learning } & & 0.95 & 0.81 \\
\hline LTRL1 & 0.92 & 0.84 & 0.16 & & \\
\hline LTRL2 & 0.85 & 0.72 & 0.28 & & \\
\hline LTRL3 & 0.87 & 0.75 & 0.25 & & \\
\hline LTRL4 & 0.90 & 0.80 & 0.20 & & \\
\hline LTRL5 & 0.96 & 0.92 & 0.08 & & \\
\hline
\end{tabular}

